\title{
Construction and Practice of Assessment and Evaluation System for Vocational College Teachers Based on New Development Ideas
}

\author{
Hui ZHANG* \\ Wuhan Institute of Shipbuilding Technology, Wuhan, Hubei, China \\ 747724184@qq.com \\ ${ }^{*}$ Corresponding author
}

Keywords: Key performance, New development concept, Professional development of teachers, Assessment and evaluation system.

\begin{abstract}
Human resources are the first resources for the construction and development of vocational colleges. The construction and development of Vocational Colleges and universities must be integrated with and harmonized with the professional development of teachers. Exploration and practice of reform in Universities Based on the post management as the starting point, to the reform of the wage system performance is leading to service teacher occupation development oriented, continue to promote the reform of colleges internal personnel allocation system, explore the construction of the occupation college teacher evaluation system based on the concept of new development, providing a continuous power for the coordinated development of health institutions.
\end{abstract}

\section{Introduction}

In the past ten years, Chinese has introduced the reform of the management system set up in employment system as the core of the implementation of the post performance salary system as the core of enterprise income distribution system reform, promote the construction of modern occupation education system, deepen the reform of teaching occupation education is the core of school enterprise cooperation, improve the quality of education and teaching, especially was held in June 2014 since the reform and opening of the third national occupation education conference in Beijing, the development of Chinese occupation education has entered a new period of development, the reform into the deep water area.

The higher occupation education China closely around the "National Long-term Education Reform and Development Program (2010-2020)" and the implementation of the overall requirements of the reform of personnel distribution system, based on the practice of reform in order to explore the college, to the post appointment management as the starting point, to the reform of the wage system performance is leading to service for the development of teacher occupation the guide, continued to promote the reform of colleges internal personnel allocation system, explore the construction of College Teachers' occupation evaluation system of new development concept based on the reference sample with hope for the construction of the development of Higher Vocational colleges.

\section{The Institutional Background of Teachers' career Development}

Since 2011, with a new round of employment as the starting point, according to the education reform and development plan of national overall reform of the personnel system in Colleges and universities, the reform of personnel distribution system of innovation as a breakthrough, to perfect the system construction as the focus, the regulations and measures for the hospital to conduct a comprehensive review and revision successively, the formulation and implementation of the plans implementation plan, staff recruitment plan, professional and technical post grade employment management, professional appointment management, professional technical position low hire low vocational staff appraisal management, performance salary allocation system of personnel distribution system, smooth and efficient completion of a new round of personnel distribution 
system reform.

The implementation of the system of personnel distribution system, strengthen the growth of students work idea, form teachers "Want me to grow up" to "I want to grow up" self motivation, promote the development of teachers' occupation ability, human resource allocation mechanism of formation of professional and technical personnel to the teaching flow, technology flow of workers to practice teaching positions, optimize the allocation of human resources structure, forming a pattern of distribution of interests income to the teaching practitioners, highlighting the central status of education and teaching, and promote the healthy and harmonious development of College education.

\section{Implement Key Performance Management and Improve the System of Examination in School}

In order to improve the effectiveness of management services and enhance the scientificity, systematicness and integrity of assessment management, we have developed a hierarchical examination management method and implemented classified assessment management.

The comprehensive assessment of "three in one" of functional departments, on the basis of adjusting the establishment of institutions, optimizing the scope of responsibilities of the departments and improving the post responsibility system, tries to carry out the "three in one" assessment of functional departments' performance, key performance indicators and service object satisfaction.

Based on the two level management, the "five elements" management of teaching units is carried out for two levels of teaching units, such as teaching and operation, student education and management, enrollment and employment, school enterprise cooperation, scientific research management and other five elements.

Objective management of service institutions and independent accounting units, and implementation of target responsibility management for logistics service group, book information center, affiliated technology enterprises and other independent accounting units.

Based on the classification assessment of job responsibilities, according to professional and technical personnel, management staff and workers on the job responsibilities, the implementation of classification management to employment oriented, examination results and their assessment allowances linked dry Department reward performance total wages and the functional departments of the middle-level cadres in me, improve the quality of training of college administrative management efficiency, service quality and personnel.

\section{Building a Multi-dimensional Assessment System to Promote the Development of Teachers' Professional Ability}

In the implementation of the classification assessment management of the total performance evaluation system, build and improve the ability to promote teachers' occupation development teacher evaluation system to lead target, system for the pilot to formulate and improve the implementation of teacher evaluation system, teachers and other professional and technical personnel to actively adapt to the general requirements of higher occupation education development and the reform of the personnel system, to further promote the culture to enhance the quality of College students.

\section{Improve Teachers' Ability to Teach and Evaluate Teachers' Teaching Quality Scientifically}

Improve the Evaluation System of Education and Teaching Quality. According to the laws of education and teaching and related teaching principles and methods, we should formulate assessment indicators and evaluation methods, and gradually achieve all-round, whole process and monitoring teaching quality assessment and evaluation system, so as to promote the scientific and standardized teaching work.

Classification and Determination of Quality Evaluation Standards for Teaching Work. Teaching quality for training teaching staff, full-time teachers, part-time teachers and teachers of 
public sports were established and evaluation standards of different, external and fanpin teaching staff by the teaching unit reference college relevant assessment methods, combined with the actual situation, formulate relevant measures for assessment, examination results as reappointment or fanpin on the basis of.

The Implementation of the Quartet Evaluation. According to different teachers' jobs were developed for different types of teaching teachers, classroom teaching, sports training teaching, experiment teaching and student evaluation and teaching evaluation table of observer evaluation table, etc. have different evaluation table, teachers' teaching quality evaluation by teaching quality evaluation, teaching unit student evaluation, teaching evaluation and subtraction (observer comprehensive performance for other construction work situation) of four parts (i.e., four evaluation) and a combination of different teaching personnel setting calculation method of different weights, reflects the characteristics of hierarchical evaluation system, highlight the vocational education concept, to improve the teaching ability of the teachers improve the quality of teaching.

Optimize the Incentive Mechanism of Assessment. Educational departments according to the assessment at the end of each semester for quality assessment of teaching evaluation, according to the full-time teachers, part-time teachers, training teaching staff three class teaching staff assessment examination results were sorted as teacher appointment, promotion, or hire the main reference assessment management and task arrangement. On the training of teaching staff, full-time teachers two consecutive or within the duration of in the teaching quality evaluation of three ranking after the $1 \%$, to be adjusted to the non vocational low hire or full-time teaching positions; part-time teachers for two or three times within the duration of the work in teaching quality evaluation ranked $1 \%$. A year no longer to arrange the teaching tasks. The evaluation of teachers' teaching workload and quality of work, whether they have completed the rated workload or not, is linked to their performance wages, forming an effective assessment and incentive mechanism.

\section{Carrying Out the Quantitative Assessment of Scientific Research and Improving the Ability of Teachers' Scientific and Technological Service}

In order to fully mobilize the teachers and other professional and technical personnel of scientific research work enthusiasm, professional and technical personnel of scientific research objective and impartial assessment, develop professional and technical personnel of scientific research workload assessment methods such as documents, the provisions of the basic work of all kinds of professional and technical personnel shall be completed accordingly, according to the rank and position of professional and technical personnel of professional and technical properties positions were provided for basic scientific research standard of all types of professional and technical personnel. The research work of the assessment results as an important basis for individual scientific work engagement examination, evaluation, selection and promotion of advanced professional and technical positions, improve the teachers' teaching and research level, to promote the teaching reform, promote discipline construction, promote the development of individual and start a positive role.

Carrying Out the Assessment of Teachers' skills Training and Improving the Quality of Teachers' Double Teachers

The Establishment and Implementation of Professional Teacher Skills Training System. Institute of education has been attached great importance to teachers' double quality, and the assessment of integration of teacher training skills, has developed a double quality teachers' identification and management measures, teachers to the laboratory (enterprise) documents practical implementation measures and construction management of science and technology innovation team interim measures, regulate the system, the effect of the implementation of the assessment, improve teacher training double quality, enhance the ability to drive the double structure of team science and technology innovation ability and social service.

Pay Attention to the Training and Evaluation of Teachers' Teaching Ability and Practical Ability. Once a year in College Teaching (skills) competition, the teaching ability of teachers, 
teaching design and practice as an important part of the organization to carry out the teaching unit, through the application to the college's final preliminaries, so the whole process of development, through the organization of teachers, expert assessment and other forms, up to learn from each other and common purpose to improve. The school also formulated the "measures" on workers and service skills competition for personnel management positions and professional and technical positions, encourage the workers and service skills with proficiency in a particular line to the appropriate personnel for professional and technical positions through education, the establishment of skilled workers from the rising channel, on the other hand to improve the quality of teachers in the two division.

\section{The Implementation of the Comprehensive Assessment, the Level of Implementation of Teacher Recruitment Management}

Implement the System of Full Employment. School of basic plans in the strict and clear responsibilities on personnel recruitment system, personnel of the change from the identity management to position management, strengthening the post employment and employment after the appraisal management, gradually establish and form the staff can be hired, promoted or demoted, post treatment can be reduced, the good man to talent shows itself and full of vitality with the dynamic employment incentive mechanism.

Promote the High and Low Management of Teachers. In the school staff recruitment and engagement examination, established according to position, according to the post appointment, the competition, the survival of the fittest "employment management mechanism, develop professional and technical positions to hire management, professional technical position low hire low vocational school recruits the appraisal management approach and other documents, the teachers from the teaching quality the scientific research work, and the annual assessment, teacher job evaluation, teaching reform, curriculum training of young teachers guidance in six areas to carry out engagement examination, and not the level of setting different quantitative indicators of nuclear tests, hire unqualified in the next period of vocational high school recruits a low low hire; on the in the assessment of teaching quality, excellent teaching and research work of outstanding personnel, mobilize the teachers to improve the quality of education and teaching enthusiasm and creativity, to ensure the personnel training The effective implementation of the plan is to guide the development of teachers' professional ability.

The Implementation of the Comprehensive Assessment, Improve Efficiency in the Use of Assessment Results. School system design through the assessment of teachers' teaching, scientific research, education, curriculum construction work, the stage of the term assessment, the annual assessment, the assessment of the organic combination of the comprehensive use of teaching and scientific research and education assessment, do the evaluation contents and the actual needs of the post match performance assessment and evaluation work attitude of unity, make the evaluation results become renewal, high level and low employment or dismissal of the basis, to promote the effective implementation of teacher occupation planning and improve the quality of teachers, effectively promote the construction of teachers' team.

Reform the Method of Professional Technical Post Evaluation and Integration with the Development and Development of Colleges and Universities

Try the Method of Quantitative Evaluation of Professional Technical Posts. For the evaluation of professional titles of teachers to further standardize the work of professional and technical personnel, and fully mobilize the enthusiasm and creativity of the work, the existing provisions, combined with the National Institute in Huber province and the relevant professional and technical position of the occupation education and faculty development needs, developed a "professional and technical post evaluation method, evaluation of teachers and other professional technology from the five aspects of professional knowledge and professional level, work performance, work ability, work, occupation moral and performance, outstanding performance and ability oriented, will require, occupation education for teachers' professional titles and the basic orientation of college professional construction and development, education and teaching method 
into actual needs and in order to highlight the higher occupation education on Teachers' occupation requirements. In order to standardize the academic moral behavior of the teachers, we have set up a "academic moral standard" in the aspect of academic morality.

The Implementation of Quantitative Management of Post Setting Competition Method. School of combined institutions post setting management requirements, develop professional and technical post grade employment management approach for teachers of professional and technical positions level promotion of those quantitative evaluation from the qualifications of age, professional and technical work duties, annual and post assessment, teaching and Research Award, scientific research ability, to meet the business unit requirements set management and occupation education development.

The Comprehensive Use of the Assessment of Leverage to Lead the Career Development of Teachers. The college will pilot the quantitative evaluation of all aspects of the work situation, teachers' professional ability, actual performance, occupation ethics, applied to the Title Evaluation on Teachers' professional and technical positions, recommended level competition for work, the effective combination of institutions and personnel system reform, occupation education development requirements, colleges and development requirements. So, the implementation of scientific management, implementation evaluation, effectively guide teachers' occupation development.

\section{Conclusion}

Assessment is a systematic project. The purpose of teacher evaluation is to emphasize the professional development of teachers and the improvement of teachers' professional ability, to improve the quality of personnel training, to improve the efficiency of running schools and to enhance the social capacity of teachers. The construction of evaluation system based on mufti-dimensional concept of new development has boosted the development of teachers' professional ability. Teachers' teaching and research capabilities and social service capabilities have been greatly improved, and the social influence of colleges has been greatly improved.

\section{Acknowledgement}

This article is supported by the Specialized Committee project of Higher Education Institute of higher education of Hubei province "Research on the construction mechanism of teachers in Higher Vocational Colleges".

\section{References}

[1] CPC Central Committee and State Council. Outline of national medium and long term educational reform and development plan (2010-2020 years) [Z].

[2] State Council. Decision on speeding up the development of modern vocational education (Guo $\mathrm{Fa}[2014] 19)[\mathrm{Z}]$.

[3] Ministry of education. Action plan for innovation and development of Higher Vocational Education (2015-2018 years) [Z].

[4] Zhang Ming-E. Construction of teachers' ability in Higher Vocational Colleges from the perspective of specialization [J]. Journal of Wuhan Institute of Shipbuilding Technology, 2015 (6).

[5] Xia Chang-zheng. Assessment and evaluation of university teachers [J]. human resource management, 2017 (11). 